\title{
Fragment of life: he who suffers the pain and the nurse that welcomes the suffering
}

\begin{abstract}
He pain is a manifestation of the body to signal something outside the normal patterns. It is the fifth vital sign, and it is painful to ignore or undervalued by the health team. This work aims to reflect on and reflect on the role of the nurse in the art of taking care of the patient with pain, in addition to explaining the influence of subjectivity in perception of this signal. It was observed that the optics of pain are perceived as a signal goal, influenced only by physiological mechanisms, in detriment to the subjective. So little is private dimension value that the pain infers in each patient. The nurse, the part of the transdisciplinary team, must take your role in the control of pain, is this who provides direct assistance to the patient in a longer period of time. So, we need greater attention and commitment on the part of this professional, for immediate intervention for the full care of the needs of the client/patient, in particular, for pain relief. The pain is a manifestation of the body to signal something outside the normal patterns. It is observed that the sick expresses in several ways. Are patients considered critics often chronic degenerative disease, in addition to the injuries that contribute to the increase of physical pain, interfering with quality of life, increases the suffering, causing excitement, anxiety, fear, anguish.
\end{abstract}

Volume 2 Issue 4 - 2018

\author{
Carvalho Mara Villas Boas,' Mendes Eliane \\ Terezinha de Castro² \\ University unifeob, Brazil
}

Correspondence: Carvalho Mara Villas Boas, University unifeob, Centro universitario fundação de ensino otavio bastos, dr. Otavio da silva bastos avenue, 2439. Sao joao da boa vista, Sao Paulo, Brazil, Tel +55 19 99165-4913;

Email carvalho-mara@uol.com.br

Received: June 10,2018 | Published: August 22, 2018

\section{Uncovering paths in the art of care/pain care}

The desire is to open this reflection with fragments of analysis, that is, fragments of life of the sick, that puts in presence human beings: the one that suffers with the pain of a disease and the other one that receives the suffering, the nurse.

Thinking of chronic and acute pain, with this proposal, we opted for the approach, based on these guiding questions: - How nurses can care for the person in the face of pain? How would the patient like to be cared for through pain? These questions enable us to unveil paths to caregiving in the process of receiving pain, which goes beyond technical and scientific knowledge, since caring also involves empathy, listening, patience, zeal, pain control, and autonomy.

Trying to make sense of a pain that is framed in subjectivity in itself, is present in the being that suffers from it, real, as a challenge, regardless of whether the pain is physical or psychic, because it is always a limiting phenomenon. An imprecise boundary between the body and the psyche is between the self and the other.

Leloup, ${ }^{1}$ emphasizes that the cares of the body do not exclude the cares of the soul, and the cares of the soul (psyche) do not dispense with the consideration of the ontological and spiritual dimension of man. Care is an integral part of life. No human being is able to survive without care. Historically, man has always had the need to be cared for, from his birth to his final moments, also extending care to everything that contributes to his survival, such as the provision of food, water, shelter, among other necessities.

Leloup ${ }^{1}$ also considers that caring includes, besides the body (food and clothing), caring for the psyche, the images and the archetypes that animate it, taking care of its desire and the orientation that it would give, caring for the other through prayer. It is now important to take care of being. It is the same as saying that we should "care" particularly for what is neither sickly nor deadly in us. Thus, the nurse's gaze is not on the disease or the patient first, but on what is beyond the reach of illness and death in it.

The nurse must perceive the sick as people, with a memory, a life history, which includes the past, the present and the difficult future perspectives permeated by anguish, fear, and unfathomable questions, especially when it comes to people before serious illnesses. One should cease to see them as body-objects, given to the hands of medical science. It is essential to begin to perceive them, too, as our teachers, because there is always something important to tell us, to teach us. To perceive them, to understand them as human beings, who really are, and who, in the situation of patients, depend, propose, request, act and react, and yet, in spite of all the circumstances to which they are subject, dream and feel the need to organize their lives, although, almost always, is the last time they do or try to do it.

It is understood that pain is a symptom that refers to the local sensation caused by an injury, and suffering refers to a global, psychic and bodily disturbance, causing its strict neurobiological mechanisms, being also that the pain is explained essentially by a disturbance that shakes the psyche. ${ }^{2}$

There are different definitions for pain. The International Association for the Study of Pain presents it as "an unpleasant emotional and sensory experience associated with potential or current tissue damage described in terms of such damages." Dame Cicely Saunders, the founder of the modern hospice, taking this description as a basis, deepened its meaning, coining the expression total pain, which includes, in addition to physical pain, mental, social and spiritual pain. Failing to consider this more comprehensive appreciation of pain is one of the main causes why patients do not receive adequate relief from painful symptoms. 
The lesion is located in the body. Pain is lived wrongly in the body, but in fact it is in the brain, both the painful sensation in the self and the painful emotion. The pain seems to us abroad and remediable. It bothers everyone as a temporary evil. ${ }^{2}$

It is observed that a great majority of health professionals do not know what pain means when they talk about it. ${ }^{3}$ Pain has two important characteristics: the first is that we are facing a dual phenomenon: on the one hand, the perception of an unpleasant sensation; on the other, the emotional response of the patient and her. The second characteristic is that the pain can be felt as acute and therefore transient, or chronic and consequently persistent.

Acute pain has a definite time of onset, objective physical and subjective signs and exaggerated activity of the nervous system. Chronic pain, is constant, continues beyond a period of six months, with the nervous system adapting to it. In patients with chronic pain, there are no objective signs even when they exhibit visible changes in their personality, lifestyle, and functional ability. This type of pain requires an approach that addresses not only the treatment of the causes of pain, but also the treatment of biological, psycho-affective, social, spiritual and cultural consequences.

Through interpersonal relationship, establishing the therapeutic bond of trust, and human care, one must be willing to perceive the other, in the present moment, in a process of transformation, whose objectives point to a single direction: to promote the quality of life while there is life.

Mayeroff ${ }^{4}$ understands that ... " to take care of another person, I must be able to understand her and her world, as if I were within this ... I must be able to be with her in her world, , to feel 'inside' what life is like for her, what she strives to be, and what she needs to grow".

As mentioned by Buber, ${ }^{5}$ the human being is distinguished by its relation to other beings and/or objects. The relationship with another human being is a state in which one recognizes the other as subject and with him cares

Martin Buber's I-Tu work is inexorably linked to life, in which reflection and action (logos and praxis) are closely related. The reflection and action of human care concerns the I-Thou relationship and/or I- Thou relationship.

Buber $^{5}$ gave the name "I-Thou" to the relationship in which the decisions are all shared. It is important to note that the interrelation, made possible by the sharing of decisions, exercised between human beings who think, feel, decide, perceive, have their own beliefs and values, interact with the environment, play their roles in it, are, in fact, establishing patterns of care, usually mutual, non-dominant or dominated.

In reflection on the world of the "I-It", we see the imposition by power, by force, symbolic or not, because the desire of the caregiver is to manipulate the other, often transforming it into an object, into a field of experimentation. The care recipient can not be used as a tool for the caregiver's purposes. Frequently, however, relationships occur in an impersonal way, in which the caregiver performs his work correctly, efficiently, but only in observance of the technical aspect. The procedures are performed in any body, impersonal, devoid of spirit, soul. This type of relationship is characterized by the personobject relationship. In the "I-Thou" world, the exercise of power is never used because the "my" desire is to accept within me the person (or object) in front of me.
Boff, ${ }^{6}$ addressing the issue of caring, says that this action is more than an act, stating that it is an attitude that encompasses more than a moment of attention, zeal and care, representing an attitude of occupation, concern, accountability and affective involvement with the other, something transcendental, supernatural.

In this way, the health professional should be the channel that facilitates listening in a sensitive way, whatever it is, and always perceive it as the echo of a quieter and higher voice. It is able to transmit to the sick person that the nurse is trustworthy, we are safe and we are consistent and are competent in caring for beings.

What can you do with the pain of the other? What is the proposal in the art of caring for nursing in the face of pain? The answer lies in the power to change the way we listen to the suffering patient in his or her inner suffering. By the way of receiving suffering, of refining with the patient and of presenting the decisive words that will change the unbearable symbolic evil, in which the nurse will become a guiding thread, of the reception, of his knowledge, through the administration of the prescribed medications of the hour, of the escutatory through his unconscious so that the pain finally calms down.

People who go to a hospital walk the path of patience, living up to the denomination that is attributed to them as a patient. They are separated into sectors, according to the disease or dysfunction of which they are carriers, or by the pathophysiology found.

From the moment the patient is admitted to the hospital, he is entering a new world that, although he is depersonalized, is able to establish a situation of hope, an opportunity to recover his health, to preserve his life. Based on the understanding of this reality, despite the various limitations, the hospitalized patient, adopting a coherent behavior, will be able to obtain the maximum possible result in the course of his hospitalization.

It is also common for patients to experience great discomfort, either by inadequate management of their bodies, or by the appearance of new symptoms, or by the very uncertainty of obtaining positive responses from their bodies to the therapeutic resources adopted to which they are subjected during treatment, in the usual situations that accompany them in this process and on the threshold of life and death.

Knowing history and its evolution is fundamental to understanding the logic of the classic way of collecting a person's health and illness data. Great contribution is attributed to the German poet of the eighteenth century, Goethe, which leads us to reflection, that, "we only see what we know". In order to use clinical reasoning, it is fundamental to reflect on what should be known to formalize nursing care. It is still fundamental to see the forms of the body; the functioning of the body; the body's responses to aggressions; how diseases and health are produced in people; the influence of the environment, culture, religions, different working processes and the particularities of each one of them to suffer and cure their evils. ${ }^{2}$

The relate to someone with the other, an immersive and plasticizer signif way, is what Heidegger ${ }^{7}$ calls "concern" that provides the basic features of having consideration for others and be patient with each other. Consideration and patience with others are not considered to be moral principles, but this embodies how one lives with others through experiences and expectations. 


\section{Awareness of the approach of pain: what the nurse needs to ease the crossing of pain}

The pain is of the sick. Do not ask the patient if he allows himself to be touched; at every moment people are invaded, the body, the soul, the spirit. I feel like a broken machine. An empty ship. Care is far from true. They are inhuman matters, there is nothing human. ${ }^{8}(d-4)$

They look at their pressure, their temperature ... they take me to the bath, it's like they're dealing with a doll. They take off my nightgown, move my body like a damaged machine. How many pains. ${ }^{8}(d-6)$

These testimonies clearly express the experience lived through pain. The first resources to contain this collapse, and that are slow to come, are the cry and the word. The most primitive antidote against the pain that people have always resorted to is the cry, when it can be emitted, then the words that resonate in the head, and which attempt to bridge the known reality of before the continuity of pain, devoid of of care and that, unknown, of today. ${ }^{2}$ Experience shows us that words are trying to transform the diffuse body pain in a concentrated pain in the soul.

The person is a being of relationships and therefore always presents a relationship with himself and with the world as beingwith and being-himself. The patient with a disease, with a pain, lives because of a medical visit, an examination, the time of the drug to be administered and other care. Anyway, you need attention. All this causes the subject to organize his strategy of coping with the heavy demands that disease imposes.

The pain of the treatment is horrible. Ah! It's a terrible pain! It is a pain of expectation. It is a pain that is very frightening, especially with uncertainty about the future.... There is physical pain, which is the pain you have for cancer. I take medicine. I take morphine. I drink, because I have a lot of pain, and if I do not take I do not walk... There is also the emotional pain. It's a pain that hurts a lot. Let's assume, the pain of the fear of dying. Sometimes I think like this: if I were to die, fall here and die, it was a beauty, but it's that fear of you going back to the hospital. It's that pain of you being alone, without any of your family members. It is a pain inside you, and having to think that you will have to lie in bed, do not know how long, do not know what awaits you. It's distressing. It is a pain in the chest, it is a pain that comes from here. There is an hour that I say: "Is it that today I am feeling a physical pain or is it that I am feeling an emotional pain today?" $8(d-8)$

Reading and re-reading these reports, one can understand that the sick person, especially a chronic degenerative illness, expects from the health professionals, especially the doctor and the nurse, greater solicitude in the treatment and respect for their pain as a "call" to be looked at and cared for in the dimension of pain. It is seen in the above verbalizations that there are several forms of pain faced, and time is experienced by each patient in a singular way, because they often feel "careless" when it comes to their pain, which is sometimes treated, in a non-holistic way, which characterizes detachment from caring in relation to emotional and spiritual pain, as well as physical pain. In this sense, the statements clearly portray the daily care given to this type of clientele. Health professionals fail to realize that, along with pathophysiological pain, there is an existential dimension of pain. In this mismatch, both sides lose opportunities for approximations.

Suffering is understood as the experience of impotence with the prospect of unrelieved pain, a situation of illness that leads to interpret the empty life of meaning. Suffering is therefore more global than pain and, fundamentally, synonymous with diminished quality of life. Since pain can be defined as a disturbance, a sensation in the body. Suffering, by contrast, is a more comprehensive and complex concept.

Faced with the vulnerability of pain and suffering, there is the art of caring which is an intentional act to solve the problem of the other, knowing how to listen, welcoming people's stories, seeing what is beyond words, feeling the pains and afflictions, the organs, hearing their answers of limits and potentialities, and, finally, to listen not only with the stethoscope but with the third ear. Knowing how to listen by perceiving the requests for help from the body, and developing care planning built together with the patient and his / her family and with the transdisciplinary look, thus being very likely to be successful. ${ }^{8}$

The first idea that pain is the sensation of a wound, goes beyond physical pain, there is the psychic pain that is the wounding of the soul. It is the disorientation of someone who is losing a part of himself. They are faced with extreme inner tension, confronted with a desire within themselves that remains dormant, until they realize that pain comes from the possibility of the arrival of finitude. ${ }^{2}$ It is time for nurses to rethink and be the guiding thread in the way of listening to the suffering patient, through the intervention of welcoming suffering, refining with it and presenting the humanized, interactive care/care, where a rhythm to the drive disorder, so that the pain finally calms down. ${ }^{8}$

\section{The patient with pain, takes the time of waiting, and the care}

Another thing: I wish that when we called, the nurses, would be more helpful, especially when I call because I'm in pain. They say it's gone. You in pain, the pain increases, you cry, and nothing.... Every time I go to the hospital I stay sometimes, more than a week, without seeing my children. It's very difficult, I miss them and they miss me. Sometimes internal because I have a lot of pain, due to lack of air, infection. See how my abdomen is, look at the size, the respiratory distress it causes in people. ${ }^{8}$

We know the importance of the health professional, doctor, nurse; more precisely with respect to the psychic factor, must interfere with the genesis of all personal pain, the guiding thread of the I-body, the I-consciousness, the endoperceptor-ego, the unconscious I-memory, the inhibiting self. Being that the psychic factor is one of the main causes of the painful emotion, whose mechanisms remain unexplored.

Nasio $^{2}$ observes that the self operates because two simultaneous perceptions: it perceives at the same time a pain that the patient locates at the level of the external lesion, and a state of internal commotion that invades him. These perceptions, mixed in the experience of the same painful affection, are, however, very different.

There are several dimensions of human suffering, valuing a holistic view of the human being, we have to pay attention to them:

Physical dimension - is the biggest cause of suffering. Progressive deterioration of the body, preventing physical functioning and relationship with others. It affects the person as a whole, he can easily go beyond this alarm function. The mild, moderate and severe pain, being that the untreated severe pain can cause the person to ask for his own death. 
All these conflicts can be expressed and interrelated as can be observed in the speech presented:

Another important thing that sometimes leaves a lot to be desired about pain: Sometimes you need to beg, cry, for them to bring pain relief. I find it very important, they should develop greater sensitivity and believe the pain of people ... out our other pains, be hospitalized here, feel nausea, vomiting, can not eat what you feel like. ${ }^{8}(d-7)$

Psychic dimension - is the dimension of suffering that often arises from confronting the inevitability of death. It is characterized by a change of mood, a sense of loss of control over the process of dying and death.

Different ways of understanding each other's pain generate possibilities for making changes in the construction of existence in order to courageously face the challenges of life and death.

It is believed that having underestimated pain also constitutes a facet of the pain faced by patients in the advanced stage of the disease. This is one of the symptoms that also generates anguish and limitations.

What got to do so much chemotherapy, I suffered a lot. There were so many vomiting, weakness, pain, nausea, so much suffering for nothing. Look at me, I'm skin and bone, with my belly grown, short of breath, this is not life. Before I had a thread of hope, now I see darkness ahead of me. What bothers me most is being so helpless. I was so active, now I can not do anything else. This disease is a monster, I do not even like to pronounce that word. ${ }^{8}(d-11)$

For Heidegger, ${ }^{7}$ death is ultimately the possibility of absolute impossibility of presence. In this way, death unfolds as the most appropriate possibility, irremissible and unsurpassable. As such, she is a privileged dependent. This existential possibility is based on the fact that the presence is essentially open to itself and this in the way of precedence-itself.

This existential moment of non-healing approximates being-todeath. Being-to-the-end becomes, phenomenally, clearer as being- for this privileged possibility of presence. Having cancer is an experience characterized as complicated, difficult, which generates confusion and uncertainties, causes changes in lifestyle, makes one perceive body fragility, entails perplexity. So the diagnosis of a cancer is considered as a blow to your destiny.

Social dimension is the dimension of suffering marked by isolation, created precisely by the difficulty of communication felt in the process of illness, of the process of dying, and the presence of solidarity and acceptance is fundamental.

Accordingly, as reminds ${ }^{10}$ Saunders, pain should be evaluated in addition to their physical size. It should be added that the emotional, social and spiritual dimensions, integrated and inseparable, which involve suffering to a greater or lesser degree in the person who experiences it, must also be taken into account.

The verbalization below clearly reveals the social pain so frequent in this clientele who experiences cancer.

Sometimes the medicine ends at home, I need it for pain and I have no money to buy, I get five hundred and eighty reais. How can we survive on so little money? You can not even afford the market expenses. To help A. (companion), he likes to drink, he always exaggerates, and that's when it's hard for me. I do not know what to do. Actually, I can not do anything. I am dependent on people's goodwill. (crying). ${ }^{8}$

Spiritual dimension - is the loss of meaning, direction and hope. It is when the patient confides to his spiritual counselor his "soul pain". We all need a sense - a reason to live and a reason to die.

I was already hospitalized for almost two months, and I saw the professional being there, with the patient, she complained of pain until she died. She was my roommate, she died on my side. (crying) She screamed in pain, and a nurse came and told her: "that she was soft, that she was soft-bodied." It got into my soul when I heard her say it, you know? - The nurse told her to stop screaming because he was bothering others... I witnessed every moment of my friend, I felt for the person, because those screams it came in my mind, in my soul. After she died, that the room was silent, I still had her screams in my head. I went to my house with her screams in my head! (D-8). ${ }^{8}$

It is possible to perceive in this testimony that the patient before the very reality that circumscribes his existence feels anguished as an end to his own existence. The possibility of death isolates man from himself. It is an insurmountable possibility, because the extreme possibility of existence is its renunciation of itself. It is only in recognizing the possibility of death, in assuming it as an anticipatory decision, that man finds his authentic being.

The existence of pain already includes the dimensions of Being in the emotional, social, spiritual, and physical realm. Doctors, nurses, care lines fail to alleviate the pain of patients. Some ignore the nature of pain, others do not accurately diagnose the source of pain, or fail to evaluate the patient at regular intervals to detect new pain-causing processes that require new therapies, and others do not believe in the patient's description of pain.

Through the analysis of the discourses, there is the call made by the voice of the conscience when being before the illness, precisely, to call to nothingness or to its last and radical form that is death.

\section{In this sense, it is worth emphasizing a speech:}

Even my ex-husband has come to visit me. He was a person who never heard me, never knew how to do it. For you to see, he left me when he learned of the disease, he already has another living in the same house. (crying) It is not easy, I have no hope of anything, I am in this bed, here completely immobilized. I have done annual preventive examinations, I have always been to the doctor, I have never been sloppy. ${ }^{8}(d-3)$

The woman, as a presence, does not dispose about the occurrence of her life as she reveals in this situation, and the present and the future can mean the success or failure of what is absorbing her. The future takes the form of the anticipatory decision, from living to death, and man remains strange to all the seductions of worldly possibilities.

The abandonment to the being is, therefore, the only attitude that the thought can lead.

What I feel, in this trajectory that I am experiencing, is that the health professionals lock themselves up and do not care about the other's problem, they do not get emotional about anything, the pain of the other person is poor in spirit. First you need to work and do 
what you like. One has to really like each other. What we see are many professionals disgruntled, grumpy, are without patience. ${ }^{8}(d-9)$

It can be seen in this discourse that the patient has a clear perception and feeling of the condition of passivity and distancing of health professionals who, in some way, maintains contacts as being mundane. In this sense, each person experiences moments of transition, being divided between their own world and that of others, passing then, to witness constant changes in their daily lives, some slow and others very fast, not providing space for thinking and feeling the situations present as means in themselves. The ethical commitment of the health professional should ensure quality of life and assistance to the person, in a philosophy that contemplates respect, that is, there is a reciprocal relationship between taking care of another person and taking care of myself, humanized care.

Hospitalization is one of the elements that significantly afflicts the patient since, from the moment of his entry, he already suffers the process of depersonalization, loss of autonomy and decision-making power. In the case of cancer patients, they are stimulated to passivity, submission and surrender. Hospitalization also demand a restriction of expression of feelings, your fears and your pain. ${ }^{10}$ The verbalization below shows how this woman who experiences the dying process would like to be cared for.

He would get closer to the patient, stay longer beside him, try to listen to him more. He paid more attention to what he meant, that is, perhaps what he meant, but he could not. It would give him more opportunity to express his pain, to let him cry his fears, to mourn injustices, to mourn his suffering. ${ }^{8}(d-11)$

If the dialogue includes respect for the dignity of the patient, at the same time it also expresses the recognition of autonomy. Autonomy means self-government, self-determination of the person making decisions that concern their lives, their health, their physical and mental integrity, their social relations. Autonomy refers to the ability of humans to decide what is "good" for you, or what makes up your "well - being"."

Autonomy expresses the human essence as freedom of choice, first and foremost, as the possibility to choose in relation to everything that concerns its own person or to the people loved by it, or, also, the forced relation with the professionals that the answer, as you can see in the speech below:

Do not let me suffer any more than I have suffered. Do not leave me alone. I'm very afraid of what's going to happen to me. I'm afraid of the dark, I'm afraid when night comes. I wanted to live my life more with my children, I wanted to live more intensely, I did not want to have suffered so much. What I have left is to die with dignity. ${ }^{8}(d-11)$

Speaking of the meaning of caring for pain control in the voice of the sick, subjects of the described reflections, has led us to understand that the reality of their daily lives is organized around the "here" of their bodies and the "now" lived in the present. This speech expresses, as a reality, the educational approach to recover the US from the weakened human person, especially in the culture in which we live, in which the patient experiences his pain in the face of life and death and is stigmatized as a patient, still little seen in their real needs.

The speeches ask the health professionals for attention whose quality of care is not only the result of technical competence, but also that of a greater human sensitivity.
This institutionalized world, which includes hospitals, treatment protocols, or even absence of care, experienced by the patients we hear, presents itself as a harsh reality. Every human being reacts with a certain fear to the incapacity, to the diminution of potentiality, to the sometimes humiliating dependence, the solitude, the uncertainty of when and how his own trajectory will take place in the face of illness. $^{12}$

These fears were evidenced in the voice of the patients in different ways. The team that assists the patient in pain, of finitude must be attentive to veiled signs, verbalized or simply manifested by nonverbal expressions, that make possible the perception of the existence of these fears, and thus of possession of the knowledge of the existing reality, can fully exercise his or her role as caregiver, providing the comfort to soften the pain, the comfort of the company, a word of encouragement, affection, welcome, without frivolities, or simply, his stay in respectful silence at his side.

Pain is what is most terrible in human experience and the fact that so often accompanies the evolution of degenerative chronic disease, bringing threat to personal integrity and breaking future prospects woes.

It is necessary for the health professional to develop the necessary sensitivity, putting into practice the humanitarian fundamentals of his academic formation, his personal trajectory, as indispensable to the perception and containment of the suffering experienced by the patient in acute and chronic pain and also in the pain of his soul, that is, total pain.

\section{Conclusion}

Pain is an experience in which biological, emotional and cultural aspects are linked in an indivisible way, and in its teaching-learning it is necessary to provide information so that these aspects can be properly considered, investigated and approached before the pain of the other. It is an education that transcends the knowledge of human cells, how they become aware of their survival, reproduce, love and react to the aggressions of the world of the birth of life and death.

It is understood that the health professional needs the clinical reasoning, to know the history of the patient, since it is the tool that has to arrive at the diagnosis of the problems of the sick people, in the case the control of the pain. The complexity of the forms of human survival that are hospitalized requires much more than the cognitive domain of the professional, in the case of being a nurse, since it is necessary to develop affective and psychoactive capacities, psychomotor to collect data, attributes with feelings, perceptions of each one about life, death, and its particularity.

Therapeutic interventions should, whenever possible, act in the cause of pain and suffering, and therapies that interfere little in the physiology and normal behavior of the individual, that are less complex, less expensive and with the minimum potential of complications and effects, are desirable adverse effects.

The concept of quality of life and respect for ethical principles in health should permeate the teaching activity, research and assistance, including the process of therapeutic decision-making focused orthothanasia.

The assistance experience represents the possibility of integrating the concepts that involve the study of pain and its management. The 
training to include care for patients with pain performed by all health professionals in an integrated manner.

One of the fundamental goals of medicine is precisely to alleviate human suffering caused by disease. It deals with human pain and suffering at the phenomenological level, while painful symptoms that require an urgent intervention in the art of caring and worthy care of the entire professional health team are not privileged in a humanistic perspective, in which compassion, the acceptance, respect and understanding of pain and human suffering, never losing sight of the whole, their values, culture, beliefs and life choices.

Based on the present reflection of pain, it is believed that it is possible to affirm that this study also signals to an ethical-political intervention, so that the desired in the practice of a profession is constituted by real and plausible values and not only ideological.

The clinical evaluation of pain begins with: Evaluation and measurement of pain; physiological correlations of pain; subjective measures of pain intensity; major scales and scores (visual analogue scale, numeric scale, categorical scales, questionnaires and inventories; registration;. ethical aspects should always believe in the patient 's complaint if he feels pain; inform patients that effective pain relief is important; teach the patient how to communicate their pain, organize the script for pain assessment and record the data, establish the frequency for the evaluation, establish communication flow between the patient and the transdisciplinary team. ${ }^{13}$

The patient must have in the art of caring for pain a nurse who listens not only to what the illness consists of but also the effects of pain in his life on his aspects of total pain. A nurse should not adopt an automatic way of characterizing suffering, but rather be a sensitive and humane listener.

Pain is one of the most feared human suffering, of extreme relevance to both the individual and the health and society team. In particular, the nursing team is the one that is the most relevant in its composition, since it is the one that spends the most time and contact in the care of the sick patient. ${ }^{13}$

Pessini $^{3}$ further understands that physicians, nurses who use drug therapies are too shy to prescribe opioid medications because of basic ignorance of the magnitude of doses required to combat acute and chronic pain.

These described sufferings can be felt as a threat to the patient in relation to the meaning of life, loss of control and weakening of the relationship with others, since the process of pain and suffering intensifies the isolation and interrupts the ordinary forms of contact with others. ${ }^{14}$

\section{As the speech below shows:}

You need a lot of willpower to live, that's the most important thing. Because, if you let the shuttle drop - let's talk like that, you knock down a husband, a son, a mother, a father, bring down the whole family. So while you are sick, you have to keep smiling because it encourages others. I'm like this, half whining, of course. Also, no one is made of iron. If someone comes to talk to me, it's not for everyone, but we have to vent, it's important to talk. Another thing I think is important is having the will to live. ${ }^{8}(d-8)$

\section{Acknowledgements}

None.

\section{Conflict of interest}

The author declares no conflict of interest.

\section{References}

1. Leloup JY. Caring for the being: Philo and the therapists of Alexandria 6th ed. Petrópolis: Vozes; 2001.

2. Nasio J. THE BOOK OF Grief and Love. Zahar, editor; 2017

3. Pessini L. A bioethical reflection on pain, suffering and death. Org. Onofre Alves Neto et al. Pain Principles and Practice. Porto Alegre: Artmed; 2009. p. 345-352.

4. Mayeroff $M$. The art of living and serving others to serve oneself. Rio de Janeiro: Record; 1971

5. Buber M Me, Trad Tu. Newton Achilles Von Zuben. 5th ed. São Paulo: Centauro; 1987.

6. Boff L. Know how to take care: Ethics of the human - compassion for the earth. Petrópolis: Vozes; 1999.

7. Heidegger M. Being and time. Trad. Márcia de Sá Cavalcanti. 3rd ed. Petrópolis: Vozes; 1993. p. 1-2.

8. Carvalho MVB, Brito SVB. The nurse and the art of caring/care: from the healed body to the disfigured body by the reverse of death. Nurs Palliat Care. 2017;2(4):1-7.

9. Carvalho MVB; Brito SVB. Care in the process of dying in the perception of women with cancer A Phenomenological Attitude. Publisher: New Academic Editions; 2017.

10. Carvalho MVB. Crossing existential pain in the face of the dying process. Castro DSP, et al. Existence and Health. Fenpec/UMESP-Sobraphe, São Bernardo do Campo, 2002. p: 221-227.

11. Saunders C. Hospice and palliative care: an interdisciplinary approach. London: Edward Arnold; 1991.

12. LeShan L. Cancer as a point of mutation: a manual for people with cancer, their relatives and health professionals. São Paulo: Summus; 1992.

13. Muñoz DR, Fortes PAC. The principle of autonomy and free and informed consent. In: Introduction to bioethics. Brasilia DF. Org. Costa SIF, Bottle V, Oselka G. Federal Council of Medicine. 1998:53-70.

14. Pepper CAM. Cancer pain: bases for evaluation and treatment. Rev The World Health Palliative Care. 2003;27(1):98-110. 